\title{
MS34-P03 | POLYMORPHISM OF R-ENCENICLINE HYDROCHLORIDE: ACCESS TO THE HIGHEST NUMBER OF STRUCTURALLY CHARACTERIZED POLYMORPHS USING DESOLVATION OF VARIOUS
}

\section{SOLVATES}

Kons, Artis (University of Latvia, Riga, LVA); Berzinš, Agris (University of Latvia, Riga, LVA); Rekis, Toms (University of Bayreuth, Bayreuth, GER)

R-encenicline (R)-7-chloro-N-quinuclidin-3-yl)benzo[b]thiophene-2-carboxamide) hydrochloride (Enc-HCl) a partial, selective agonist of the $\alpha-7$ nicotinic acetylcholine receptor which was developed for the treatment of cognitive deficits in schizophrenia and Alzheimer's disease. Here, we report an experimental, structural and computational study of neat polymorphs of Enc- $\mathrm{HCl}$. In solid form screening numerous solvates including hydrates have been obtained, and their desolvation produced twelve neat polymorphs and for ten of them crystal structures were determined. The crystal structures of precursor solvates/hydrates were found to be structurally similar and related to those of desolvated phases, which was consistent with the observed phase transitions among the related pairs. In addition, a comparison of the thermodynamic stability of polymorphs were performed using differential scanning calorimetry data and solvent mediated slurry-bridging experiments. The energy ranking of ten polymorphs were obtained by DFT calculations with different functionals and/ or dispersion correction methods. 